\title{
PERSPECTIVES OF STACK AND ENVIRONMENTAL MONITORING IN THE SURROUNDINGS OF A WASTE-TO-ENERGY PLANT
}

\author{
LUCA ADAMI ${ }^{1}$, MARCO SCHIAVON ${ }^{1}$, MARTINA FERRAI ${ }^{2}$, LORIS DALLAGO ${ }^{2}$, \\ ELENA CRISTINA RADA ${ }^{3}$, MARCO TUBINO ${ }^{1} \&$ MARCO RAGAZZI $^{1}$ \\ ${ }^{1}$ Department of Civil, Environmental and Mechanical Engineering, University of Trento, Italy \\ ${ }^{2}$ ISER Srl, Italy \\ ${ }^{3}$ Department of Theoretical and Applied Sciences, University of Insubria, Italy
}

\begin{abstract}
Waste-to-Energy (WtE) processes respond both to the emerging need for reducing the flow of waste into the environment and, at the same time, to the increasing demand for energy. Despite, these evident advantages, $\mathrm{WtE}$ plants still present some critical issues regarding the emissions of heavy metals into the atmosphere, which are regulated by the environmental legislations but, concerning the European Union, are regarded as groups of metals with no consideration of the different carcinogenic potential of each metal. In addition, there are uncertainties on the estimation of the balance of carbon dioxide, which depends on several factors like transportation, type of incoming waste, processes in use and secondary emissions. Despite great improvements in air pollution control from this sector, persistent organic pollutants are still emitted by WtE plants. Therefore, the implementation of adequate environmental monitoring (EM) plans is essential to monitor the impact of WtE plants in their surroundings, especially in the presence of the population, fields and pastures. In view of these considerations, this paper aims to provide guidance on basic and novel approaches that are necessary for a comprehensive monitoring of the impacts of a new WtE plant in terms of air quality and public health. A case study regarding the EM plan proposed for a new WtE plant will also be reported as an example.

Keywords: ambient air, soil, deposition, sediments, dioxin, heavy metals, gasification, waste management.
\end{abstract}

\section{INTRODUCTION}

The increasing demand for energy that has taken place since the last century, combined with the increasing need for reducing the flow of waste into the environment, resulted in the great opportunity of producing energy from waste and in the development of the so-called waste-to-energy (WtE) sector [1]. The contribution of this sector towards the achievement of the United Nations' Sustainable Development Goals number seven (Affordable and Clean Energy) and eleven (Sustainable Cities and Community) has already been recognised by the scientific literature in this field [2], [3].

Generally, WtE processes include the direct or indirect combustion of waste or refuse-derived fuel (RDF), which is produced by aerobic treatments of the residual fraction of municipal solid waste (MSW). Being thermal processes, both methods lead to the generation of thermal energy from the combustion of a fuel. The latter can be directly the RDF in the case of direct WtE plants (e.g.: incinerators) or the gas generated by the thermal treatment of waste/RDF, i.e. the syngas [4], [5]. In this last case, WtE plants are commonly regarded as indirect processes and include different gasification treatments, pyrolysis and combinations of these treatments [6]-[8].

MSW incinerators are the first example of WtE technologies [9]. Historically, MSW incinerators were depicted as a threat for human health, especially for their contribution in terms of dioxin in the atmosphere. In the last decades, the WtE sector has undergone rapid changes in the air pollution control lines to limit the emissions of dioxin, heavy metals, 
particulate matter $(\mathrm{PM})$ in general, nitrogen $\left(\mathrm{NO}_{\mathrm{x}}\right)$ and sulphur $\left(\mathrm{SO}_{\mathrm{x}}\right)$ oxides [10]. Besides the use of renewable sources, $\mathrm{WtE}$ was recently recognised as one of the cleanest approaches for energy production, thanks to the improvements made in terms of air pollution control [11]. Nowadays, modern WtE plants may include electrostatic precipitators and bag-house filters (for PM removal), multi-stage scrubbing (to remove acids and $\mathrm{SO}_{\mathrm{x}}$, with the optional addition of activated carbon to remove dioxin, hydrocarbons in general and metals), selective or non-selective catalytic reduction (for $\mathrm{NO}_{\mathrm{x}}$ removal) and, recently, selective catalytic oxidation (for dioxin removal) [10]. Further improvements are expected by the WtE sector from the general point of view of sustainability, especially concerning the minimisation of the solid residues (e.g., bottom ashes) and the recovery of chemicals [12]-[16]. These expected improvements will allow the $\mathrm{WtE}$ sector to comply with a vision of circular economy. Specifically, the literature recently highlighted the positive role of indirect combustion and bottom ash vitrification in a circular economy perspective [17].

However, some potential criticalities still exist, especially concerning the role of heavy metals [18]. In addition, as large combustion installations that partly burn non-biogenic fractions of waste, WtE plants generate net positive emissions of carbon dioxide $\left(\mathrm{CO}_{2}\right)$ into the atmosphere, with direct impacts on the climate. Non-biogenic $\mathrm{CO}_{2}$ contributions also derive from the use of other fossil fuels to ignite the waste and to carry out the vitrification process of the bottom ashes, as an option to landfilling. Methane $\left(\mathrm{CH}_{4}\right)$ and coke are usually adopted for those purposes, respectively. Indirect $\mathrm{CO}_{2}$ net emissions that must be considered to complete the $\mathrm{CO}_{2}$ balance derive from the transportation (positive contribution to the net $\mathrm{CO}_{2}$ generation) of waste and from the avoided emissions related to both energy recovery strategies and the choice of performing the co-generation of thermal and electric energy (negative $\mathrm{CO}_{2}$ contribution). The net $\mathrm{CO}_{2}$ generation is normally calculated as an estimate based on standard emission factors regarding positive contributions (auxiliary fuel combustion and waste transportation) and the negative contributions (extra thermal energy, obtained by energy recovery strategies, and electric energy production from a reference mix of fuels, which may be compensated by electric energy production by a steam turbine in the plant). The $\mathrm{CO}_{2}$ generated by waste oxidation can be estimated by the carbon content of the input waste, which requires periodical characterisation. Thus, the amount of $\mathrm{CO}_{2}$ generated by a WtE plant strongly depends on the input waste, whose composition may not be constant over time. Therefore, the estimation of $\mathrm{CO}_{2}$ emissions through emission factors is subject to a high degree of approximation. A continuous monitoring system for $\mathrm{CO}_{2}$ concentration at the stack level would reduce the degree of uncertainty and avoid performing chemical characterisation of the input waste.

In the European Union, the emissions from WtE plants in the atmosphere are regulated by the European Directive 2010/75/EU [19]. The authorisation processes of a WtE plant is regulated by the European Directive 2014/52/EU [20] that reviewed the Directive 2011/92/EU [21] in several aspects: 'purely' procedural requirements, screening, quality and monitoring [22]. Directives (Art. 1 of 16) shall apply to the assessment of the environmental effects of those public and private projects which are likely to have significant effects on the environment. This Directive describes the procedure to evaluate the Environmental Impact Assessment (EIA) of a single project to ensure an integrated pollution prevention and control on the environmental matrices (e.g. soil, water, air, ecosystems). A specific section of the EIA Directive describes the EM plan with the aim to conducting cumulative exposure and risk assessment pre- and post-intervention [23].

An EM plan should monitor the area potentially influenced by the plant and the expected impacts as more completely as possible. All the environmental comparts that could be influenced by the activities of the plant should be correctly identified, as well as the pollutants 
monitored. To create a reference base to compare the situation when the plant is in operation, it is important to evaluate the pollution level before its construction. If critical impacts cannot be excluded during the plant construction, a monitoring activity should be planned during this phase too.

In the light of the importance of correct EM plans for the $\mathrm{WtE}$ sector, the present paper is intended to provide guidance on the basic approaches that are necessary to monitor the impacts of a new WtE plant in terms of air quality. In addition, this work presents other new and unconventional strategies that would allow for a comprehensive monitoring of a WtE plant from the point of view of its impacts on air quality and on the exposure to air pollutants. Such new approach responds to the need for overcoming the uncertainties that characterise this sector in terms of (1) the emissions of heavy metals and persistent organic pollutants (POPs), (2) the role of secondary emissions and (3) its carbon footprint. These aspects are here discussed also by considering the case study of the EM plan proposed for a new WtE plant.

\section{BASE APPROACH}

Hereby we refer to the case study of a project for a new WtE plant located near the border between the provinces of Trento and Bolzano (North Italy). The project consists in a thermal treatment of industrial waste finalized to produce energy (electricity and heat), through the technology of indirect combustion, with final vitrification of the ashes. Input of the new plant consists in RDF (European Waste Catalogue - EWC - code 19 12 10) and in sorting non-hazardous residues (EWC code 1912 12) for a total amount of 95,000 t/year. Estimated net production of electric energy is $100 \mathrm{GWh} /$ year, with a maximum thermal power of $69 \mathrm{MW}$. The main stack of the WtE plant is designed $45 \mathrm{~m}$ high, with an internal diameter of $1.8 \mathrm{~m}$. The scheme of the new plant consists in the main following parts: heating furnace, gasifying reactor, temperature monitoring and product analysis. Moreover the thermal line is completed by the presence of a heating recovery system, dry off-gas purification line with catalytic removal of nitrogen oxides and spent reagent storage systems, turbo generator with nominal capacity of $17 \mathrm{MW}$ and connected vapour cycle system. The outgoing airflow rate from the primary stack is $107,000 \mathrm{Nm}^{3} / \mathrm{h}$.

The EM plan proposed for the case study presented above is partly based on a conventional monitoring scheme that considers classical environmental matrices for air contaminants: exhaust gas, ambient air and soil. Noise pollution and other environmental matrices like superficial water basins and groundwater are considered by the plan but are not reported in this paper. According to the EM plan, ambient air concentrations and soil concentrations should be measured before, during and after the construction of the plant. One critical aspect, which may influence the significance of the monitoring activity, is the location of the sampling points. The most appropriate strategy consists in locating the sampling points where the highest impacts are expected. The choice of the sampling points can then be made on the basis of the results of the dispersion modelling that is part of the environmental impact assessment procedure. In addition to the expected hotspots, especially in the case of soil concentrations, sensitive areas could be selected, such as kindergarten, schools and parks, where children might be exposed to the contaminants by accidental soil ingestion. Regarding the contaminants to monitor, concerning ambient air concentrations, heavy metals and, in general, PM10 are the air pollutants considered by the EM plan of the case study presented here. The choice of these air contaminants to monitor is related to the results of the dispersion modelling and to the health impact assessment, which highlighted that the role of dioxin is negligible with respect to that of heavy metals. The monitoring of soil concentrations concerned a larger variety of pollutants (heavy metals, aromatics, phenols, chlorinated 
compounds, polycyclic aromatic hydrocarbons, plant protection products, dioxin and other chemicals) according to the legislation on the concentration limit values of pollutants in soils [24].

\section{ADVANCED APPROACH}

In addition to the classical monitoring approach involving stack emissions, pollutant concentrations in ambient air and soil and noise, other techniques are very useful to characterise the impacts of a new installation and, specifically, a new WtE. Such techniques are not routinely included in EM plans, but their potential in deepening the understanding of how the environment is influenced by the plant is worth consideration for future environmental impact assessment procedures. Some methodologies would provide additional information to measure the footprint of a WtE plant in the surroundings. Other methodologies would overcome issues related to the $\mathrm{WtE}$ sector that have been recently pointed out [15].

The contribution of a WtE plant in terms of air pollutants could be evaluated by two unconventional methodologies that have been developed in the last five years. Specifically, two methods are particularly appropriate to monitor the influence of a plant in terms of persistent organic pollutants (POPs). The first method consists in the characterisation of the sediments of a pond, possibly located downwind and within a few kilometres from the plant. By knowing the sedimentation rate of the pond and by collecting a sediment core, it is possible to characterise and quantify the POPs that have deposited as sediments to the bottom of the pond over the years. This method allows reconstructing the history of pollutant contributions in the area and, through the analysis of the fingerprints of chlorinated compounds like dioxin and through the so-called "diagnostic ratios" between different polycyclic aromatic hydrocarbons, the identification of the dominant source(s) of POPs in the area is made possible [25]. Indeed, every source emitting dioxin is characterised by a specific profile of the different congeners in the exhaust off-gas of a combustion plant [26]. In spite of large approximations that must be considered on the fate of POPs in the atmosphere and on their partition between gaseous and particle phases, the detection of a similar profile in other environmental matrices might reveal that the most probable origin of the contamination could be the combustion plant under observation. Another unconventional methodology allows obtaining the same information: the characterisation of the atmospheric depositions to soil. By placing bulk deposition samplers in the surroundings of a combustion plant, the role of the plant can be determined by a comparison between the congener profiles of dioxin and the fingerprint of the specific emitting activity [26]. Deposition samplers should be placed in strategic locations, preferably close to residential areas, schools, hospitals, fields and pastures, in order to cover all the possible routes of exposure to POPs. Indeed, in the case of dioxin, the diet is the dominant exposure route [27], since such group of toxics tend to accumulate in the food chain, specifically in fat tissues. This peculiarity justifies the importance of monitoring pastures and fields [28]. For both methodologies, the quantification of POPs can be made with high-resolution gas chromatography and mass spectrometry, after extraction with hexane and specific purification cycles [25], [26]. Both methodologies are included in the EM plan of the WtE plant presented here as a case study. Figure 1 presents the location of the monitoring points chosen for the measurement of ambient air concentrations, soil concentrations, atmospheric deposition and sediment sampling. The monitoring points were the same for ambient air concentrations and atmospheric depositions (A1 and A2) and are located close to the area of the plant. A1, located in a vineyard, coincides with the cell with the highest concentration of air pollutants that results from the dispersion model used during the environmental assessment study; A2 was chosen to characterise the role of the plant in the industrial area where the plant is located. One monitoring point for 
soil concentration (SO1) was selected as close to the cell of maximum impact for air pollutants, whereas the second monitoring point (SO2) was chosen to keep a playground under observation. The monitoring point for sediment concentrations (SE1) is located in a nearby pond.

An additional monitoring proposal concerns the speciation of the chromium released by the stack(s) of a WtE plant. At the European level, the environmental legislation established concentration limit values for several heavy metals emitted from incineration plants: cadmium $(\mathrm{Cd})$, thallium $(\mathrm{Tl})$, total chromium $(\mathrm{Cr})$, arsenic (As), nickel $(\mathrm{Ni})$, lead $(\mathrm{Pb})$, vanadium (Va), cobalt (Co), mercury ( $\mathrm{Hg})$, manganese (Mn), antimony (Sb) [19]. However, the legislation does not specify limit values for the single heavy metals (apart from $\mathrm{Hg}$ ), but establishes a limit values for the sum of $\mathrm{Cd}$ and $\mathrm{Tl}$, and for the sum of the remaining metals. Some of the aforementioned metals are listed by the International Agency for Research on Cancer (IARC) as carcinogenic (Cd, As, Ni) and possibly carcinogenic (Hg) to humans [29]. In addition, in the emissions from a WtE plant, $\mathrm{Cr}$ is composed by $\mathrm{Cr}$ III (not carcinogenic) and $\mathrm{Cr}$ VI (carcinogen to humans). Among the metals regulated by the legislation, $\mathrm{Cr} \mathrm{VI}$ and Cd have the highest carcinogenic potentials [30]. This means that, in a worst-case scenario, a WtE plant might emit a large proportion of $\mathrm{Cd}$ and $\mathrm{Cr} \mathrm{VI}$ in relation to the other metals in their respective groups and, in spite of this, would comply with the legislation. In other words, in the absence of specific limits for carcinogenic metals, the environmental authorities of a country/region could authorise a new plant to induce a non-acceptable cancer risk in the population potentially exposed to the emissions.

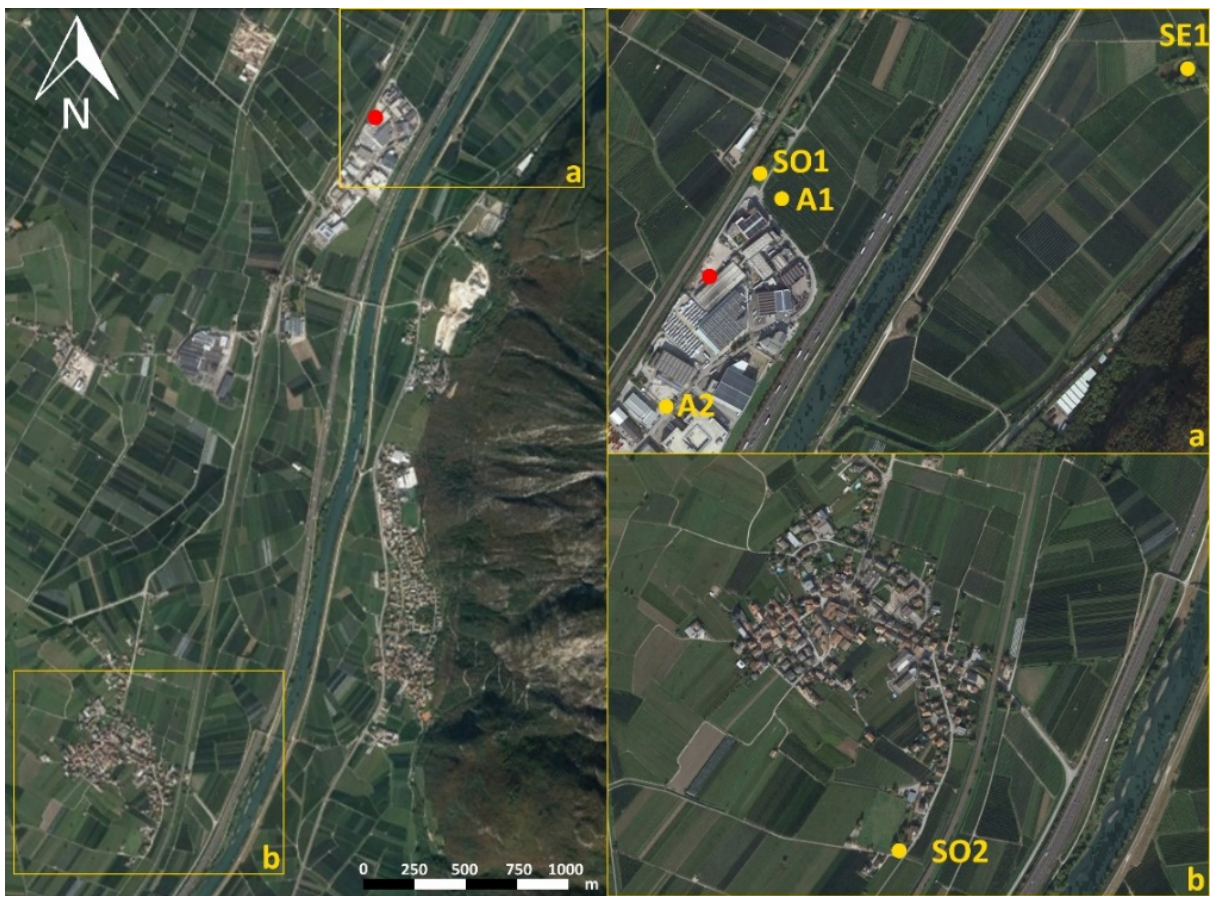

Figure 1: Location of the monitoring points for ambient air concentrations and deposition (A1 and A2), soil concentrations (SO1 and SO2) and sediment sampling (SE1) chosen for the case study; the location of the primary stack is represented by a red dot. 
Thus, a monitoring approach consisting in periodical verifications of the concentrations of the specific metals at the stack would help the detection of anomalous contributions of carcinogenic metals in the atmosphere. It is worth reminding that inhalation is not the only route of exposure to metals. Accidental soil ingestion and the diet may give non-negligible contributions to the daily dose too [31]. Therefore, a periodical metal speciation at the stack, which could be carried out by sampling and analysing the particulate matter released by the plant, would allow excluding the occurrence of non-acceptable levels of carcinogenic metals or considering the adoption of improved air pollution control technologies. The quantification of metals could be carried out with inductively coupled plasma optical emission spectrometry on particulate samples. $\mathrm{Cr}$ speciation could be determined with ion chromatography-based US EPA method 7199 [32]. This first additional monitoring approach is proposed within the EM plan of the WtE plant presented in Section 2.

The emissions into the atmosphere from a WtE plant usually do not only originate from the main chimney. Secondary emissions may play a significant role in the overall mass flow of the air pollutants released by a WtE plant. In the case study presented here, for instance, the mass flow rate of total suspended particles (TSP) released by secondary emissions are estimated to be almost $28 \%$ the TSP mass flow rate from the primary stack. The type of air pollutants released and their mass flow rates vary depending on the type of secondary emission involved. In addition, different secondary emissions may be subject to different limit values, which depend on the nature of the processes and on the fuel used (if any). The characterisation of the emissions from a WtE plant may be more complicated in the presence of diffuse emissions, i.e. the release of air pollutants in the atmosphere without any conveyance systems. However, such conditions are likely to occur in the residual municipal solid waste treatment sector only if the plant includes an aerobic biological stage. In that case, diffuse emissions (represented by an area source) may occur at the outlet of the air treatment line if an open biofilter is used [33]. Given the non-negligible role of secondary emissions, an EM plan should keep the concentrations of air pollutants under control. To this purpose, discontinue samplings at secondary emission points might be sufficient to characterise secondary contributions into the atmosphere.

The conventional monitoring approach usually focuses on local pollutants. However, the carbon footprint of a WtE plant could be also easily assessed by installing a non-dispersive infrared (NDIR) sensor for the monitoring of the concentrations of greenhouse gases at the point of release of the exhaust gas. Given the non-negligible contributions expected from secondary emissions, installing NDIR gas sensors also on secondary stacks would allow for a direct measurement of the carbon footprint of the whole plant. In addition, the direct measurement of greenhouse gases could turn useful to calibrate the average $\mathrm{CO}_{2}$-equivalent $\left(\mathrm{CO}_{2 \mathrm{eq}}\right)$ emission factors that are usually adopted to estimate the carbon footprint from specific processes. The monitoring of $\mathrm{CO}_{2 \text { eq }}$ concentrations (and consequently of the $\mathrm{CO}_{2 \mathrm{eq}}$ mass flow rates, which can be calculated from the airflow rate) at all the emission points of a WtE plant could help detecting priorities in the adoption of strategies to reduce the emissions of greenhouse gases, by focussing, for instance, on the transportation of waste and/or on carbon sequestration processes.

\section{CONCLUSIONS}

The present paper analyses perspectives of stack and environmental monitoring of a new WtE plant to be built in north Italy, discussing the results of the base approach (due to existing European Directives) and to an advanced approach due to necessary improvements suggested by the specificity of the case studied that can find broader application in the WtE field. The advanced approach proposed includes two unconventional methodologies developed in 
the last five years to monitor the influence of a WtE plant in terms of persistent organic pollutants (POPs), in particular the characterisation of the atmospheric depositions to soil.

In particular, the first method describes the characterisation of the sediments of a pond, located downwind and in the neighbourhood of the plant. This allow (1) to reconstruct the contribution of pollutants in the surrounding area and (2) to identify the dominant sources of POPs through (1) the analyses of the fingerprints of chlorinated compounds and through (2) the so-called "diagnostic ratios" between different polycyclic aromatic hydrocarbons.

The second methodology proposed consists in placing bulk deposition samplers in strategic positions (e.g. public areas and buildings like schools, hospitals and parks, residential areas, fields and pastures) in the surroundings of the plant, comparing the congener profiles of dioxin and the fingerprint of the specific emitting activity from the stacks.

In addition to the two unconventional methodologies we propose (1) the speciation of the chromium released by the stacks of the $\mathrm{WtE}$ plant with the aim to quantify the cancerogenic effect due to the presence of Cr VI in the total Cr emitted and (2) the specific analyses of the emissions from secondary chimneys.

Although the application of first unconventional method is limited by the presence of a pond in the neighbourhood of the plant, the second methodology as well as the speciation of the chromium and the analyses of the secondary points of pollution emission can be considered innovative approaches for the characterization of a WtE plant that aim to minimize its environmental footprint.

\section{ACKNOWLEDGEMENT}

The authors wish to thank PA Holding for the financial support to the research that was the starting point of the present article.

\section{REFERENCES}

[1] Brebbia, C.A., Telles, J.C.F. \& Wrobel, L.C., (eds), Boundary Element Techniques, Springer-Verlag: Berlin and New York, pp. 11-13, 1984.

[2] Osifchin, N. \& Vau, G., Power considerations for the modernization of telecommunications. Proceedings of the Fourth Annual Portable Design Conference, pp. 137-142, 1997.

[3] Test Methods for Evaluating Solid Wastes, Physical/Chemical Methods; U.S. Environmental Protection Agency, Office of Solid Wastes, SW-846. www.epa.gov/epaoswer/hazwastes/test/main.htm. Accessed on: 23 Jun. 2015.

[4] Bratanow, T. \& De Grande, G., Numerical analysis of normal stress in non-Newtonian boundary layer flow. Engineering Analysis, 6(2), pp. 20-25, 1985.

[5] Klinghoffer, N.B., Themelis, N.J. \& Castaldi, M.J., Waste to energy (WTE): an introduction. Waste to Energy Conversion Technology, eds N.B. Klinghoffer \& M.J. Castaldi, Woodhead Publishing: Cambridge, pp. 3-14, 2013.

[6] AlQattan, N., Acheampong, M., Jaward, F.M., Ertem, F.C., Vijayakumar, N. \& Bello, T., Reviewing the potential of Waste-to-Energy (WTE) technologies for Sustainable Development Goal (SDG) numbers seven and eleven. Renewable Energy Focus, 27, pp. 97-110, 2018.

[7] United Nations, About the Sustainable Development Goals. www.un.org/sustainabledevelopment/sustainable-development-goals/. Accessed on: 21 Dec. 2018. 
[8] Costa, M., Curcio, C., Piazzullo, D., Rocco, V. \& Tuccillo, R., RDF incineration modelling trough thermo-chemical conversion and gaseous combustion coupling. Energy, 161, pp. 974-987, 2018.

[9] Bosmans, A., Vanderreydt, I., Geysen, D. \& Helsen, L., The crucial role of Waste-toEnergy technologies in enhanced landfill mining: A technology review. Journal of Cleaner Production, 55, pp. 10-23, 2013.

[10] Ribeiro, A., Soares, M., Castro, C., Mota, A., Araujo, J., Vilarinho, C. \& Carvalho, J., Waste-to-energy technologies applied for refuse derived fuel (RDF) valorization. Lecture Notes in Electrical Engineering, 505, pp. 641-647, 2018.

[11] Lombardi, L., Carnevale, E. \& Corti, A., A review of technologies and performances of thermal treatment systems for energy recovery from waste. Waste Management, 37, pp. 26-44, 2015.

[12] Ragazzi, M. \& Rada, E.C., Multi-step approach for comparing the local air pollution contributions of conventional and innovative MSW thermo-chemical treatments. Chemosphere, 89, pp. 694-701, 2012.

[13] Xu, H., Lin, W.Y. \& Romagnoli, A., Technological review on enhancing the energy efficiency of MSW incineration plant. Proceedings of the 2018 Asian Conference on Energy, Power and Transportation Electrification, 8610756, 2019.

[14] Makarichi, L., Jutidamrongphan, W. \& Techato, K., The evolution of waste-to-energy incineration: A review. Renewable and Sustainable Energy Reviews, 91, pp. 812-821, 2018.

[15] Carneiro, M.L.N.M. \& Gomes, M.S.P., Energy, exergy, environmental and economic analysis of hybrid waste-to-energy plants. Energy Conversion and Management, 179, pp. 397-417, 2019.

[16] Ardolino, F., Berto, C. \& Arena, U., Environmental performances of different configurations of a material recovery facility in a life cycle perspective. Waste Management, 68, pp. 662-676, 2017.

[17] Rada, E.C., Ragazzi, M., Torretta, V., Castagna, G., Adami, L. \& Cioca, L.I., Circular economy and waste to energy. AIP Conference Proceedings, 1968, 030050, 2018.

[18] Schiavon, M., Ragazzi, M., Rada, E.C., Magaril, E. \& Torretta, V., Towards the sustainable management of air quality and human exposure: Exemplary case studies. WIT Transactions on Ecology and the Environment, vol. 230, WIT Press: Southampton and Boston, pp. 489-500, 2018.

[19] European Union, Directive 2010/75/EU of the European Parliament and of the Council of 24 November 2010 on industrial emissions (integrated pollution prevention and control). Official Journal of the European Union, Document 32010L0075.

[20] European Union, Directive 2014/52/EU of the European Parliament and of the Council of 16 April 2014 amending Directive 2011/92/EU on the assessment of the effects of certain public and private projects on the environment Text with EEA relevance. Official Journal of the European Union, Document 32014L0052.

[21] European Union, Directive 2011/92/EU of the European Parliament and of the Council of 13 December 2011 on the assessment of the effects of certain public and private projects on the environment Text with EEA relevance. Official Journal of the European Union, Document 32011L0092.

[22] Arabadjieva, K., 'Better Regulation' in environmental impact assessment: The amended EIA directive. Journal of Environmental Law, 28(1), pp. 159-168, 2016.

[23] Barzyk T.M., Conlon K.C., Chahine T., Hammond D.M., Zartarian V.G. \& Schultz B.D., Tools available to communities for conducting cumulative exposure and risk 
assessments. Journal of Exposure Science and Environmental Epidemiology, 20, pp. 371-384, 2010.

[24] European Union, Directive 2004/35/CE of the European Parliament and of the Council of 21 April 2004 on environmental liability with regard to the prevention and remedying of environmental damage. Official Journal of the European Union, Document 32004L0035.

[25] Argiriadis, E., Rada, E.C., Vecchiato, M., Zambon, S., Ionescu, G., Schiavon, M., Ragazzi, M. \& Gambaro, A., Assessing the influence of local sources on POPs in atmospheric depositions and sediments near Trento (Italy). Atmospheric Environment, 98, pp. 32-40, 2014.

[26] Rada, E.C., Ragazzi, M. \& Schiavon, M., Assessment of the local role of a steel making plant by POPs deposition measurements. Chemosphere, 110, pp. 53-61, 2014.

[27] Sasamoto, T., Ushio, F., Kikutani, N., Saitoh, Y., Yamaki, Y., Hashimoto, T., Horii, S., Nakagawa, J. \& Ibe, A., Estimation of 1999-2004 dietary daily intake of PCDDs, PCDFs and dioxin-like PCBs by a total diet study in metropolitan Tokyo, Japan. Chemosphere, 64(4), pp. 634-641, 2006.

[28] Schiavon, M., Ragazzi, M. \& Rada, E.C., A proposal for a diet-based local PCDD/F deposition limit. Chemosphere, 93(8), pp. 1639-1645, 2013.

[29] International Agency for Research on Cancer, IARC Monographs, Classifications. http://monographs.iarc.fr/ENG/Classification/latest_classif.php. Accessed on: 20 Dec. 2018.

[30] U.S. Environmental Protection Agency, Integrated Risk Information System (IRIS). www.epa.gov/IRIS/. Accessed on: 20 Dec. 2018.

[31] Yousaf, B., Amina, Liu, G., Wang, R., Imtiaz, M., Rizwan, M.S., Zia-ur-Rehman, M., Qadir, A. \& Si, Y., The importance of evaluating metal exposure and predicting human health risks in urban-periurban environments influenced by emerging industry. Chemosphere, 150, pp. 79-89, 2016.

[32] United States Environmental Protection Agency, Method 7199 - Determination of hexavalent chromium in drinking water, groundwater and industrial wastewater effluents by ion chromatography. www.epa.gov/sites/production/files/201512/documents/7199.pdf. Accessed on: 20 Dec. 2018.

[33] Schiavon, M., Ragazzi, M., Torretta, V. \& Rada, E.C., Comparison between conventional biofilters and biotrickling filters applied to waste bio-drying in terms of atmospheric dispersion and air quality. Environmental Technology, 37(8), pp. 975982, 2016. 